\title{
LEITURA DE POESIA: “PAISAGENS COM CUPIM”, DE JOÃO Cabral de Melo Neto
}

\author{
Felipe Oliveira de Paula* \\ UFMG \\ fopaula@yahoo.com.br
}

RESUMO: Inicialmente, o que pode definir um texto como poesia é a forte marca de subjetividade. Ocorre que a subjetividade expressa no poema deve ser pensada a partir de sua especificidade e pela sua dinâmica na própria forma do texto. Nessa perspectiva, proponho interpretar o poema "Paisagens com cupim", de João Cabral de Melo Neto, na trilha do pensamento de Theodor Adorno (2003) de que quanto mais escondida estiver a relação cristalizada entre o eu e a sociedade, mais bem acabado esteticamente é o poema. A forma poética capta melhor um movimento histórico no momento em que menos se preocupa em expor uma simples consequência das relações vigentes em uma dada situação. $\mathrm{O}$ que importa aqui não é uma temática social, mas como o sujeito poético trabalha formalmente elementos dispostos na realidade.

Palavras-chave: Poesia. João Cabral. "Paisagens com cupim”. Forma literária.

ABSTRACT: Initially you can set a text as poetry is the strong subjectivity mark. Is that subjectivity expressed in the poem should be thought but by their specificity and for its own dynamic in text form. From this perspective I propose to interpret the poem "Paisagens com cupim" by João Cabral de Melo Neto, on the trail of the thought of Theodor Adorno (2003) that the more hidden are crystallized relationship between the self and society is better aesthetically finished the poem. The poetic form better captures a historical movement at a time when less bother to expose a simple consequence of the existing relations in a given situation. What matters here is not a social issue, but as the poetic subject works formally elements arranged in reality.

Keywords: Poetry. João Cabral. "Paisagens com cupim”. Literary form.

* Doutorando em Estudos Literários pela Universidade Federal de Minas Gerais (UFMG). Revista Texto Poético I ISSN: 1808-5385 | Vol. 20 (1o sem-2016) - p. 189 
"O paraíso do porvir é uma reação da sociedade objetiva." José Guilherme Merquior

Para começo de conversa, vou pontuar rapidamente três características essenciais da noção de poesia, como gênero literário, que será aqui trabalhada. Para definir um momento, a caracterização da poesia, tal como a tratamos, começou a ser modificada sobretudo pelos irmãos Schlegel e Novalis com a denominada Escola de Jena, durante o Romantismo Alemão, a partir mais ou menos de 1790. Até então a poesia servia para classificar as espécies lírica, épica e dramática. Com a transformação dos grandes poemas narrativos e dramáticos em prosas, o termo poesia passou a se confundir com lírica. Como afirma José Guilherme Merquior (1997, p.17), "no exame da literatura moderna, um termo pode ser praticamente empregado pelo outro". Seguindo esse pensamento, utilizo em minha exposição o termo poesia.

É importante atentar que uma consequência dessa identificação é a poesia ser pensada como contendo uma função linguística específica. A poesia é o tipo de mensagem linguística em que o significante é tão visível quanto o significado, isto é, "em que a carne das palavras é tão importante quanto o seu sentido". Na tentativa de exemplificar o trabalho de invenção poética, Paul Valéry (2007, p. 203) diz que, no momento da criação, o poeta briga com a matéria verbal, "obrigado a especular sobre o som e o sentido ao mesmo tempo, para satisfazer não somente o harmônico, o período musical, mas também as condições intelectuais e estéticas variadas, sem contar as regras convencionais". Em suma, "a poesia é uma arte da linguagem. A linguagem, contudo, 
é uma criação da prática" (VALERY, p. 200). Definição que pode ser incorporada para pensarmos a poesia cabralina.

Retomando a origem da palavra, poiéin, em grego, significa criação. Desse modo, podemos fazer uma breve restrição do termo e aceitá-lo, pelo menos inicialmente, da seguinte maneira: poesia é um trabalho de pensar sobre maneiras específicas de usar a palavra explorando todas suas potencialidades. Nem todo poema nem toda obra construída sob as leis da métrica contém poesia. Decorre que poesia não se confunde com o verso. Poesia pode estar também na prosa, como é visível, por exemplo, em Guimarães Rosa.

Essa é uma característica marcante da poesia e o exame atento da estrutura do poema, longe de isolá-lo do mundo, revelará em que exato nível se articula com ele. Como demonstra José Merquior (1997, p. 23), "a fidelidade ao concreto e, de certo modo, a própria mimese começa na articulação da estrutura verbal do poema".

O terceiro elemento importante para se pensar é a subjetividade, que tem um significado específico e fundante no gênero. Como evidencia György Lukács (2009, p. 246), "mesmo na lírica aparentemente mais objetiva, é precisamente essa subjetividade o que se percebe de modo imediato - e, portanto, ela é o centro sensivelmente poético da obra. A diferença é pela específica e visível ação dessa subjetividade". Para entender a poesia é preciso igualmente questionar a subjetividade nela expressa, não como mera transposição de uma possível consciência isolada dos fatores objetivos, mas sim por sua especificidade e pela sua dinâmica na própria forma do texto. Recorrendo a outro materialista, para Theodor Adorno (2003, p. 76) é preciso perceber que a configuração poética é sempre, também, "a expressão subjetiva de um antagonismo social. Mas como o mundo objetivo, que produz a lírica, é um mundo em si mesmo antagonístico, 
o conceito de lírica não se esgota na expressão da subjetividade, à qual a linguagem confere objetividade".

Dito isso, farei uma interpretação do poema "Paisagens com cupim", de João Cabral de Melo Neto, tentando perceber como a poesia está indissoluvelmente ligada à sociedade. Transcrevo-o abaixo:

\section{PAISAGENS COM CUPIM}

1

O Recife cai sobre o mar

sem dele se contaminar.

O Recife cai em cidade,

cai contra o mar, contra: em laje.

Cai como um prato de metal sobre outro prato de metal sabe cair: limpo e exato e sem contágio: em só contato.

Cai como cidade que caia vertical e reta, sem praia.

Cai em cais de cimento, em porto, em ilhas de aresta e contorno.

O Recife cai na água isento.

Bem calafetado o cimento:

ao dente da ostra, ou sua raiz, aos bichos do mar, seus cupins. 
Olinda não usa cimento.

Usa tijolo farelento.

Mesmo com tanta geometria

Olinda é já de alvenaria.

Vista de longe (tantos cubos)

ela anuncia um perfil duro.

Porém de perto seus sobrados

revelam esse fio gasto

da madeira muito roçada, das paredes muito caídas, de ancas redondas, usuais nas casas velhas e animais.

Porque Olinda, uma Olinda baixa, Se mistura com o mar na praia: que é por onde se vão infiltrar em seu corpo os cupins do mar.

3

Os arrabaldes do Recife não opõem os mesmos diques contra o rio que em horas é o mar disfarçado em maré

Lá o mar entra fundo no rio e em passos de rio, corredios, derrama-se em todos os tanques por onde a salmoura dos mangues. 
O mar por lá vai de água parda de rio, e de boca calada.

É água de mar, também salobra.

Só que sonolenta e mais gorda.

E lá no que se infiltra, quando,

O mar não rói: corrompe inchando.

Não traz cupins de fome enxuta.

Traz úmidos bichos de fruta.

4

As vilas entre coqueirais

(as muitas Itamaracás)

mais que as corrói o tal cupim:

ele mesmo as modela assim.

São aldeias leves de palha,

plantadas raso sobre a praia

com os escavados materiais

que o cupim trabalha e o mar traz.

São menos da terra que da onda:

têm as cavernas das esponjas,

das pedras-pomes, das madeiras

que o mar abandona na areia.

Menos da terra que do mar:

dos cupins que ele faz medrar

e dão tudo a carne leve

que o mar quer nas coisas que leve 
As cidades do canavial, escava-as um cupim igual. Ou outra espécie de cupim, já que o mar cai longe dali.

Igaraçu, Sirinhaém, o Cabo, Ipojuca e também Muribeca, Rio Formoso: há algo comido em seu estofo.

E outras ainda mais de dentro: Nazaré, Aliança, São Lourenço: imitam no estilo, no jeito, casas de cupim, cupinzeiros.

Cidades também em colinas, do mesmo tijolo de Olinda, também minadas por marés (ora de cana) pelos pés.

6

A paisagem do canavial não encerra quase metal. Tudo parece encorajar o cupim, de cana ou de mar.

Não só as cidades, outras coisas: os engenhos com suas moitas e até mesmo os ferros mais pobres das moendas e tachas de cobre. 
Tudo carrega seu caruncho.

Tudo: desde o vivo ao defunto.

Da embaúba das capoeiras à economia canavieira.

Em tudo para o ar de abandono de meia-morte ou pleno-sono, a esse deixar-se imovelmente próprio da planta e do demente.

7

No canavial tudo se gasta pelo miolo, não pela casca.

Nada ali se gasta de fora, qual coisa que em coisa se choca.

Tudo se gasta mas de dentro:

o cupim entra os poros, lento, e por mil túneis, mil canais, as coisas desfia e desfaz.

Por fora o manchado reboco vai se afrouxando, mais poroso, enquanto desfaz-se, intestina, o que era parede, em farinha.

E se não se gasta com choques, mas de dentro, tampouco explode. Tudo ali sofre a morte mansa do que não quebra, se desmancha. 
No canavial, antiga Mata, a vida está toda bichada.

Bichada em coisas pouco densas, Coisas sem peso, pela doença.

Bichada até a carne rala da bucha e do pau-de-jangada. Até a natureza poída, porém, inchada, da cortiça.

Eis o cupim fazendo a vez do mestre-de-obras português: finge robustez na matéria carcomida pela miséria.

Eis os pais de nosso barroco, de ventre solene mas oco e gesto pomposo e redondo na véspera mesma do escombro.

9

Certas cidades de entre a cana (Escada, Jaboatão, Goiana) Procuram se armar com aço Contra a vocação de bagaço.

Mas o aço tomado deu mal: não se fecharam ao canavial e somente em bairros pequenos seu barro salvou-se em cimento. 
E nelas (como nas usinas, que de aço também se vacinam, nas quais só a custo a ferragem vive, azul, nos meses de montagem)

a cana latifúndia em volta com os cupins que ela cria e solta, penetra ainda fundo: combate-as até a soleira das fábricas.

\section{0}

O Recife, só, chegou a cristal em toda a Mata e Litoral:

o Recife e a máquina sadia que bate em Moreno e Paulista.

Essas existem matemáticas no alumínio de suas fábricas. Essas têm a carne limpa, embora feia, em série, fria.

O cupim não lhes dá combate:

Nelas motores vivos batem que sabem que enquanto funcionem nenhuma ferrugem os come.

Mas nem na Mata ou Litoral há mais desse aço industrial para opor-se ao cupim, ao podre que o mar canavial traz, ou fosse.

(MELO NETTO, 2003, p. 235-240) $)^{25}$

${ }^{25}$ CABRAL, "Quaderna", p. 235-240. Toda referência ao poema foi retirada da obra completa publicada pela Nova Aguilar, em 2003. Como se trata de um poema não muito extenso, não mais citarei a referência com intuito de deixar o texto mais corrido. 
O poema faz parte do livro Quaderna, publicado originalmente em Portugal, em 1960. Um ano depois, junto com Dois Parlamentos (1960) e Serial (inédito), o livro foi republicado na coletânea intitulada Terceira Feira (1961).

O que liga os textos dessa coletânea é a abrangência temática já expressa em Paisagem com figuras (1955), qual seja: o Nordeste, a Espanha, o diálogo entre ambos, marcados pelo vetor comum de uma condição humana caracterizada sempre pela falta.

Quaderna se destaca também pela presença marcante da temática feminina. É a primeira vez na obra cabralina que a mulher ganha força estruturante. De modo que o livro pode ser pensado a partir de quatro grupos temáticos: reflexão sobre o processo de feitura, representado pelo poema "A palo seco"; o feminino, representado por "Estudos para uma bailadora andaluza"; a Espanha, percebida, por exemplo, em "Sevilha"; e o Nordeste, representado por "Paisagens com cupim".

No poema da série nordestina, o mesmo termo antes aplicado ao belo ("a paisagem" feminina) o é a um inseto (cupim), demonstrando a incorporação de realidades consideradas não poéticas ou antipoéticas pela tradição do discurso literário, como explica Antonio Carlos Secchin (2014).

O sujeito poético, de modo narrativo-descritivo, divide o poema em 10 blocos. Iniciando pela cidade de Recife e perpassando as cidades próximas. A ideia geral é mostrar o impacto do cupim nas cidades ao redor da capital pernambucana. No último bloco, ele volta a focar a cidade de Recife. As 10 "unidades-quadras"26 mimetizam o movimento histórico da ascensão e da decadência da economia

${ }^{26}$ Expressão de Haroldo de Campos (2013, p.85) utilizada no texto "O geômetra engajado".

Revista Texto Poético | ISSN: 1808-5385 | Vol. 20 (1o sem-2016) - p. 199 
canavieira de Pernambuco, por meio da recriação poética das cidades que estiveram (ou ainda estão) intrinsecamente ligadas ao cultivo do corte de cana. Não há rebuscamentos, idealizações ou subjetividade explícita na exposição dos blocos. A objetividade colocada por meio da terceira pessoa e "do ritmo sincopado (cai sobre o mar > cai em cidade $>$ cai contra o mar) apenas mostra, deixando ao leitor aparentemente o julgamento e a impressão daquilo que seus versos expõem" (SILVA FILHO, 2011, p. 49).

Aparentemente porque a liberdade de interpretação, ou melhor, a falsa ideia de que o poema por ser cerebral, bem-calculado, e objetivo, a ponto do sujeito poético não se posicionar e somente expor um quadro, começa a se desafazer quando examinamos os aspectos sonoros do poema. Essa análise nos permite começar a delinear uma particularização de quem fala. Nas quatro primeiras estrofes, sobressai o som de k:, que é sustentado, não só, mas em grande parte, pela repetição do verbo "cair" (9x). Se pensarmos no significado e na sonoridade da palavra, tal como configurada no primeiro bloco, perceberemos que Recife é uma cidade que cai ordenada, uma cidade que "sabe cair: limpo e exato". Percebe-se uma plasticidade nessa estrofe, uma vez que a sonoridade contribui para construção de um movimento planejado, no qual os blocos de cimento caem se encaixando e criando uma proteção da cidade contra o mar; impedindo, consequentemente, o acesso de bichos como o cupim. Vê-se que uma visão da cidade de Recife vai sendo instaurada na medida em que as potencialidades das palavras são exploradas. O sujeito poético está preocupado não apenas com o modo de encaixar a cidade, de dizer sobre o cair ordenado dela, mas também em configurar o poema para, assim como a cidade, ficar ordenado. $O$ poema não quer apenas dizer 
sobre a cidade exata, limpa, ele é exato e limpo através, sobretudo, de uma linguagem exata e limpa.

A partir do segundo bloco, a sonoridade utilizada vai ser diferente, condizente a cada local ou região descrita. O que une os blocos de 2 a 9 é a interferência do cupim na paisagem. Começando por Olinda que, ao contrário de Recife, já é uma cidade pronta: "Olinda é já de alvenaria" $(2, \mathrm{I})^{27}$. A geometria, perfil duro, é apenas aparente, já que a cidade de perto está toda corroída porque há uma abertura para os cupins se infiltrarem na Olinda baixa. No terceiro bloco, "Nos arrabaldes do Recife", a água do mar mimetiza a água do rio e, junto, leva o inseto. Os arrabaldes não são tão vigilantes, não têm o mesmo rigor que Recife, e deixam brechas para os bichos entrarem na cidade e deixar tudo oco. Já na parte 4, trata-se de um processo diferente, pois as vilas "(as muitas Itamaracás)" são erguidas a partir de materiais trabalhados pelos cupins no mar. São eles que fornecem pedras-pomes, madeiras, esponjas para construção das vilas, de modo que os lugares já nascem corroídos, ocos.

A partir do quinto bloco o sujeito poético descreverá a ação dos cupins da terra. A descrição se dá sempre em comparação ao que não é feito para evitar o contágio com os insetos. Diferentemente da cidade de Recife que se protege. Na quadra 6, não se trata mais do cupim do mar, e sim o da terra, mas que faz estrago parecido. Na "paisagem do canavial" percebe que "tudo carrega o seu caruncho/ tudo: desde o vivo ao defunto.”. Aqui vale notar o paralelismo que o poeta faz com vivo e defunto nos seguintes versos. Vivo: embaúba das capoeiras, meiamorte, planta. Defunto: economia canavieira, pleno-sono, demente. O que ainda vive (as árvores e as plantações) é descrito em seguida como

${ }^{27}$ O número arábico refere-se ao bloco e o número romano a estrofe, contidos no poema "Paisagens com cupim".

Revista Texto Poético | ISSN: 1808-5385 | Vol. 20 (1o sem-2016) - p. 201 
meia-morte. O que está morto, ultrapassado, é tudo aquilo que se refere à economia gerada pela plantação de cana. Isso acontece porque está tudo deteriorado pelo cupim, que, por sua vez, não teve nenhuma resistência. Na paisagem do canavial "tudo parece encorajar/ o cupim”.

No canavial, o cupim continua agindo por dentro, "e não se gasta com choques/ mas de dentro, tampouco explode./ Tudo ali sofre a morte mansa/ do que não quebra, se desmancha" (7). "A vida toda está bichada" (8).

O último bloco encerra a trajetória elencando características que protegem Recife. De modo geral, a imagem do cupim transmite o sentimento de corrosão ao longo da narração, mas, ao mesmo tempo, o poema é denso, consistente, todo calculado, matemático, sem estar oco. No poema não há palavra vazia, diferentemente do que acontece com as paisagens que são habitadas pelos cupins. Recife é a única cidade que não está corroída, mas não está porque se arma permanentemente contra os insetos. Recife não deixa tudo solto, à deriva, assim como o sujeito poético na construção desse poema. A ausência do bicho é fruto de um trabalho, de um esforço.

Como notou Antonio Carlos Secchin (2014), o texto percorre a temática da decomposição ou desagregação do que era matéria sólida, revelando ainda o esforço para combater a degenerescência. A paisagem do sólido ao liquefeito é sustentada por imagens de corrosão de "núcleo cupim", expandidas em duas direções: uma líquida (os cupins do mar) e outra sólida (os cupins do canavial).

O caminho litoral e interior - mar e canavial - parece problematizar o contato estético e histórico entre centro e periferia, entre modelos externos e matéria local. Essa relação se estabelece por misturas, numa transfiguração de um em outro, e, a um só tempo, conservando a tensão entre ambos, unindo-os e separando-os. 
Em certo momento, o trabalho do cupim faz alusão histórica à passagem dos portugueses em nosso país, "Eis o cupim fazendo a vez/ do mestre-de-obras português: finge robustez na matéria/ carcomida pela miséria" (8, III). O sujeito poético, a seu modo, aproxima passado e presente se referindo aos empecilhos da formação brasileira. Essa ligação acontece menos porque há uma exploração das dificuldades tão evidentes do país em temas e mais porque repete e questiona estruturalmente o gesto do mestre-de-obras, "com gesto pomposo e redondo/ na véspera mesma do escombro" (8, IV).

Os elementos locais ou regionais se sedimentam no poema como tradição descritiva presente largamente na literatura brasileira, desde Bento Teixeira, passando por Manoel Botelho, e, de forma mais problematizada, por Claudio Manuel da Costa. Havia nesses poetas uma preocupação em dar forma à nova realidade americana por meio da descrição da paisagem, um esforço estético que, ao mesmo tempo, se contradiz em sua objetividade, pois produz efeito transfigurador da realidade concreta (CANDIDO, 2011).

No poema de João Cabral em análise, a paisagem não é pura natureza descrita, não é repouso para os sentidos, até porque o sujeito poético não está questionando a paisagem em si, mas como ela vem sendo incorporada pela tradição. A natureza na obra cabralina não é buscada como uma imagem positiva, mas uma imagem que the permite refletir toda uma tradição do discurso literário. $\mathrm{E}$, no mesmo processo, qual a linguagem (entenda-se: quais palavras, qual técnica, qual sonoridade etc.) o poeta deve configurar no seu poema. A paisagem, depois de ser limpa, é aproveitável e ganha nova força, serve como elemento estruturante, mas noutra configuração. A forma da poesia cabralina nos leva, então, a pensar não só em sua poética, mas no modo de se fazer literatura e, além e entre isso, a íntima relação entre poesia e sociedade. 
O que o sujeito poético quer apreender, pela linguagem, é uma leitura da realidade, não o que resta de dados colhidos pela sensibilidade. Como assinala João Alexandre Barbosa (1975), o poema, transformado numa meditação acerca da imagem inicial, desfaz e refaz os seus termos na medida em que vai isolando o núcleo daquilo que se quer 'comunicar', isto é, antes o desgastamento operado pelo cupim do que ele próprio. Retomado o título, a "paisagem com cupim". Muito evidente, mas vale reforçar: a paisagem não pode ser pensada sem a presença constituinte do cupim. A presença do cupim indica, na verdade, o que ele retira da paisagem. A preposição "com" é irônica nesse sentido, visto que o título pode ser lido como paisagem sem...

Nesse processo de composição em que o sujeito está constantemente pensando e refazendo a imagem que lhe interessa, estabelece-se um forte diálogo com a tradição. Noutro poema, por exemplo, a palavra flor é utilizada para negar uma cristalização de sua imagem, negar um sentido já estabelecido antes de sua configuração no poema: "Poesia, te escrevia:/ flor! conhecendo/ que és fezes" (MELO NETO, 2003, p.98). O sujeito poético nega tudo o que se limita a um único modelo. É preciso pôr a imagem, a palavra, a técnica em funcionamento para daí extrair seu sentido. A partir desse questionamento da linguagem percebe-se uma orientação crítica do real.

O como fazer de Cabral deve ser visto como uma análise de soluções encontradas pela subjetividade artística diante dos problemas estéticos, cujos direcionamentos estavam marcando um tipo de arte voltada cada vez mais para pensar o processo de construção. A subjetividade do eu-poético não pode simplesmente rejeitar ou fugir da história, mas, podendo fraturála pelo vetor subjetivo, assume-se muitas vezes como parte da história e da sociedade e ao mesmo tempo como representação artística das contradições. Deixando transparecer uma luta contínua com a palavra, a 
imagem, e uma luta para conseguir uma expressão que se comunica sem grandes teorizações. Conforme Theodor Adorno, toda exigência feita à poesia é, em si mesma, social, de tal modo que o sujeito poético deve ser visto como "relógio solar histórico" (ADORNO, 2003), configurado em cada poema de maneira particular. A procura por uma cidade/poema limpa, justa, bem planejada, equilibrada, "bem calafetada" contra os bichos, que não se deixa quebrar, é uma reação a uma dada sociedade que promete, mas não cumpre. Com outras palavras, a poesia de Cabral não é estritamente confissão, mas tampouco é uma [simples] negação do mundo vivido pelo poeta. 'É preciso, portanto, pensar o conceito de subjetividade não como algo ligado apenas ao romantismo e à escrita automática do surrealismo, mas também articulado à poesia construída, como é, no caso, a de João Cabral.” (SILVA FILHO, 2011, p.42).

O "descascamento da imagem" (NUNES, 1974) é uma maneira de explorar as potencialidades contidas nas palavras, nos símbolos, nas técnicas, mas que não se realizaram porque foram negadas. Em "Paisagens com cupim", o sujeito poético escolhe um inseto para apreender um olhar diferente do local. Ele quer negar tudo aquilo que foi prometido, mas não cumprido, ele nega com isso uma negação. Tal como a imagem "flor" que tradicionalmente vem sendo pensada como adorno ou como expressão de sentimentos amorosos, mas, como propõe o poema cabralino citado acima, também é preciso saber que é "fezes": saber de onde ela vem, como se forma etc. Se pensarmos a forma da poesia numa relação dialética com a forma social, pode-se indicar que não só a poesia não conseguiu explorar todas as ferramentas disponíveis para seu aperfeiçoamento, assim como também as promessas do capitalismo com a modernização não foram tão eficientes. A aparência se mostra atraente, mas por dentro "as coisas desfia e desfaz" (7, II). 
O sujeito poético procura a extração de uma substância que, sendo inicialmente das regiões descritas, termina por afirmar-se como imagem problematizadora e problematizada daquilo que, por sob a visão das "aparências", o conhecimento busca delimitar. A industrialização (no final do poema) não significa uma solução apaziguadora, apenas isolada, haja vista que a presença do cupim já foi de tal modo afirmada que mesmo na região industrial não desfazem os riscos de podre que espreitam o homem. A abstração é a estratégia por intermédio da qual é possível retornar, pela linguagem, ao núcleo, ao concreto, das coisas e do homem.

\section{Referências}

ADORNO, Theodor. Lírica e Sociedade. In: Notas de Literatura I. São Paulo: Duas Cidades; Ed. 34, 2003.

BARBOSA, João Alexandre. A imitação da forma. São Paulo: Duas cidades, 1975.

CAMPOS, Haroldo. O Geômetra Engajado. In: Metalinguagem \& outras metas: ensaios de teoria crítica literária. São Paulo: Perspectivas, 2013.

CANDIDO, Antonio. Literatura de dois Gumes. In: A Educação pela Noite. Rio de Janeiro: Ouro sobre Azul, 2011, pp. 197-218.

LUKÁCS, György. Para uma teoria marxista dos gêneros literários. In: Arte e sociedade: escritos estéticos 1932 - 1967. Rio de Janeiro: Editora UFRJ, 2009, pp. 161-270.

MELO NETO, João Cabral de. Obra completa: volume único. Organização: Marly de Oliveira. Rio de Janeiro: Nova Aguilar, 1994.

NUNES, Benedito. João Cabral de Melo Neto. Rio de Janeiro: Vozes, 1974. MERQUIOR, José Guilherme. Natureza da lírica. In: A astúcia da mimese: ensaios sobre lírica. Rio de Janeiro: Topbooks, 1997, pp. 17-33. 
SECCHIN, Antonio Carlos. João Cabral de ponta a ponta. In: Uma fala só lâmina. São Paulo: Cosac Naify, 2014, pp. 11 -388.

SILVA FILHO, Marcos de Souza. O mar e o canavial: transfiguração do real na poética de João Cabral de Melo Neto. 2011. 107f. Dissertação. UnB, Brasília, 2011.

VALERY, Paul. Poesia e pensamento. In: Variedades. São Paulo: Iluminuras, 2007, pp. 193-200. 